Published in final edited form as:

Angew Chem Int Ed Engl. 2007 ; 46(38): 7262-7265.

\title{
Synthesis and Reactivity of Olefin Metathesis Catalysts Bearing Cyclic (Alkyl)(Amino)Carbenes ${ }^{*}$
}

\author{
Donde R. Anderson, Vincent Lavallo, Daniel J. O'Leary, Guy Bertrand, and Robert H. \\ Grubbs
}

\section{Keywords}

alkenes; carbenes; homogeneous catalysis; metathesis; ruthenium

\begin{abstract}
The evolution of olefin metathesis into a reaction routinely used to form new carbon-carbon double bonds has been enabled by the development of well-defined transition-metal catalysts. $[1,2]$ Many metathesis catalysts based on the $\left[\mathrm{L}_{2} \mathrm{X}_{2} \mathrm{Ru}=\mathrm{CHR}\right]$ scaffold have been synthesized in an effort to increase catalyst stability, activity, and substrate scope.[3-10] A significant gain in these areas was achieved after exchanging a single $\mathrm{PCy}_{3}$ ligand of $\mathbf{1}$ with $\mathrm{H}_{2} \mathrm{IMes}\left(\mathrm{H}_{2} \mathrm{IMes}\right.$ = 1,3-dimesityl-4,5-dihydroimidazol-2-ylidene), an N-heterocyclic carbene (NHC), to produce catalyst 2 (Figure 1). [5] These results are attributed to the increased $\sigma$-donor ability of $\mathrm{H}_{2} \mathrm{IMes}$ over $\mathrm{PCy}_{3}$, which increases the affinity for $\pi$-acidic olefins relative to $\sigma$-donating phosphines. [11] Additionally, exchange of the remaining $\mathrm{PCy}_{3}$ ligand with a chelating ether moiety provides a more stable complex, catalyst 3.[6]
\end{abstract}

Recently, the synthesis of cyclic (alkyl)(amino)carbenes (CAACs), in which one amino group from an NHC has been replaced by an alkyl group, was reported.[12] The greater $\sigma$-donor ability of carbon versus nitrogen results in more electron-donating ligands, as indicated by the $v_{\mathrm{CO}}$ absorption of $c i s-\left[\mathrm{Rh}(\mathrm{Cl})(\mathrm{CO})_{2} \mathrm{~L}\right]$ complexes $\left(\mathrm{L}=\mathrm{H}_{2} \mathrm{IMes}, \tilde{v}_{\mathrm{Co}}=1996,2081 \mathrm{~cm}^{-1} ; \mathrm{L}=\right.$ $\left.\mathbf{5 b}, \tilde{v}_{\text {co }}=1994,2077 \mathrm{~cm}^{-1}\right)$.[13] The exchange of an $\mathrm{sp}^{2}$-hybridized nitrogen atom for an $\mathrm{sp}^{3}$-hybridized carbon atom also changes the steric environment relative to NHCs. Although most NHCs are $C_{2 v}$-symmetric, the CAACs reported to date are $C_{\mathrm{s}^{-}}$or $C_{1^{-}}$-symmetric, which may have implications for the microscopic reversibility of the olefin-binding and cycloreversion steps in the metathesis catalytic cycle.[14,15] The unique properties of CAACs led us to explore the utility of this new class of stable carbenes as ligands in olefin metathesis catalysts.

We first chose to investigate carbenes $\mathbf{5 a}, \mathbf{b}$, which can be prepared from their respective salts 4a,b (Scheme 1).[12,16] These ligands each contain an $N$-DIPP (DIPP = 2,6-diisopropylphenyl) group and vary the steric bulk at the quaternary carbon adjacent to the carbene center, with either two Me groups (5a) or a spiro-fused cyclohexyl group (5b). Upon addition

\footnotetext{
** Lawrence M. Henling and Dr. Michael Day are acknowledged for X-ray crystallographic analysis. D.R.A. acknowledges NSF and NDSEG predoctoral fellowships. D.J.O. thanks the Mellon Foundation for financial support. R.H.G. and G.B. were supported by the NSF (CHE-0410425) and the NIH (R01 GM 68825).

* D. R. Anderson, Prof. R. H. Grubbs, Arnold and Mabel Beckman Laboratories of Chemical Synthesis, Division of Chemistry and Chemical Engineering, California Institute of Technology, Pasadena, CA 91125 (USA), Fax: (+1) 626-564-9297, E-mail: rhg@ caltech.edu, V. Lavallo, Prof. G. Bertrand, UCR-CNRS Joint Research Chem. Laboratory (UMI 2957), Department of Chemistry, University of California, Riverside, CA 92521-0403 (USA), Fax: (+1) 951-827-2725, E-mail: gbertran@ mail.ucr.edu, Prof. D. J. O’Leary, Department of Chemistry, Pomona College, 645 North College Avenue, Claremont, CA 91711 (USA), Fax: (+1) 909-607-7726, E-mail: doleary@pomona.edu

Supporting information for this article is available on the WWW under http://www.angewandte.org or from the author.
} 
of potassium hexamethyldisilazide (KHMDS) to salts $\mathbf{4 a}, \mathbf{b}$ at $22^{\circ} \mathrm{C}$ in benzene, the corresponding carbenes $\mathbf{5 a , b}$ are obtained in good conversion as observed by ${ }^{1} \mathrm{H}$ NMR spectroscopy.

Ruthenium olefin metathesis catalysts bearing a pyridine ligand typically undergo facile ligand exchange with stronger donors such as phosphines or NHCs.[17] Thus, upon addition of pyridine complex $\mathbf{6}[18]$ to an NHC, the resulting ruthenium complex is typically coordinated by a carbene ligand and a phosphine ligand (e.g. 2), rather than a pyridine ligand. However, upon treatment of pyridine complex $\mathbf{6}$ with carbenes $\mathbf{5 a}, \mathbf{b}$ (generated in situ), no evidence for the expected phosphine complexes was obtained by ${ }^{1} \mathrm{H}$ or ${ }^{31} \mathrm{P}$ NMR spectroscopy [Eq. (1)]. Instead, air-sensitive pyridine adducts $\mathbf{7 a}, \mathbf{b}$ were isolated in modest yields.

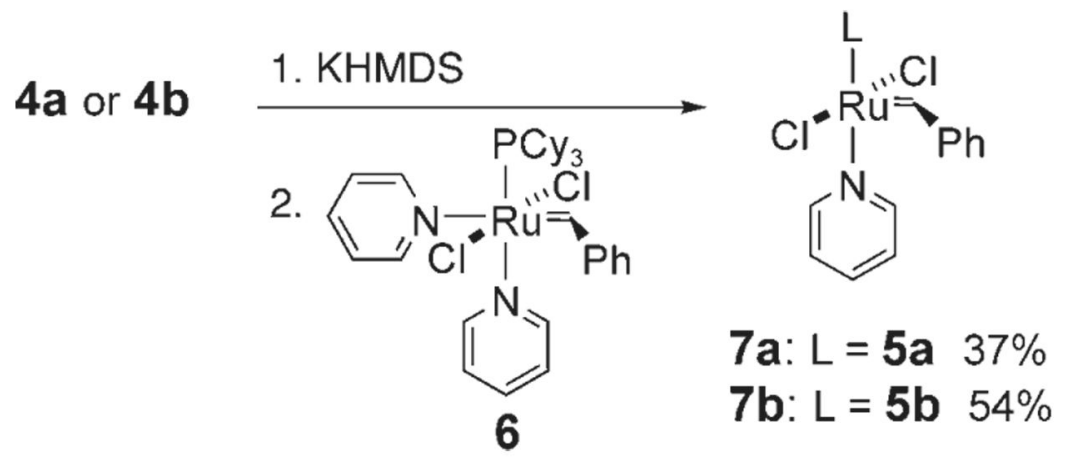

$\mathrm{X}$-ray crystallographic analysis of compounds $\mathbf{7 a , b}$ was conducted. These complexes exhibit a distorted square-pyramidal geometry with the benzylidene ligand in the apical position (Figure 2). The bond lengths and angles of the pyridine catalysts $\mathbf{7 a}, \mathbf{b}$ are similar to those of $\left[\left(\mathrm{H}_{2} \mathrm{IMes}\right)(\mathrm{py})_{2}(\mathrm{Cl})_{2} \mathrm{Ru}=\mathrm{CHPh}\right](\mathbf{8})$ (see the Supporting Information).[17] The $\mathrm{Ru}-\mathrm{C}_{\text {carbene }}$ distance is $\approx 0.05 \AA$ shorter than in $\mathbf{8}$ which is consistent with the increased $\sigma$-donating ability of CAACs relative to $\mathrm{H}_{2} \mathrm{IMes}$. In addition, the $\mathrm{Ru}-\mathrm{C}_{\text {benzylidene }}$ bond length is $\approx 0.03 \AA$ shorter in $\mathbf{7 a , b}$ than in $\mathbf{8}$, possibly a result of the trans influence of the additional pyridine ligand in 8.

The efficiency of catalysts $\mathbf{7 a}, \mathbf{b}$ was examined in the ring-closing metathesis of diethyl diallylmalonate (9) [Eq. (2)].

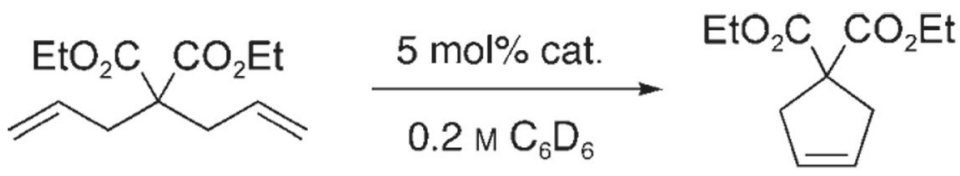

Maximum conversions to cyclopentene 10 observed by ${ }^{1} \mathrm{H}$ NMR spectroscopy were less than $50 \%$ after $24 \mathrm{~h}$ at $22^{\circ} \mathrm{C}$ or $60^{\circ} \mathrm{C}$, which is attributed to catalyst decomposition. These results are consistent with those obtained previously with pyridine-containing catalysts.[19] For comparison, complexes $\mathbf{2}$ and $\mathbf{3}$ can achieve 95\% conversion to $\mathbf{1 0}$ in 30 and $20 \mathrm{~min}$, respectively, at $30^{\circ} \mathrm{C}$ and $1 \mathrm{~mol} \%$ catalyst loading.[19]

To obtain more stable complexes, we targeted complexes 12a,b. After addition of $\mathbf{5}$ a,b (prepared in situ) to ruthenium precursor 11,[8] catalysts 12a,b were isolated and purified in good yields by column chromatography [Eq. (3)]. Chelating ether complexes 12a,b are airand moisture-stable compounds. 
$4 a$ or $4 b$

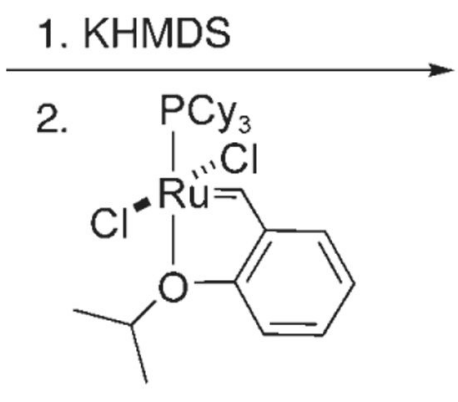

11

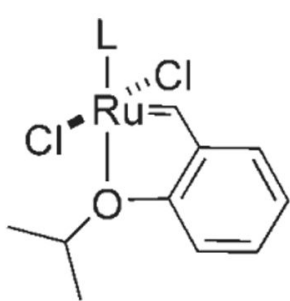

12a: $L=5 \mathbf{a} 50 \%$

12b: $L=5$ b $91 \%$

Similar to complexes $\mathbf{7 a , b}$, the solid-state structures of $\mathbf{1 2 a}, \mathbf{b}$ show a distorted squarepyramidal structure with the benzylidene moiety at the apical position (Figure 3). Comparing complexes 12 a,b with the $\mathrm{H}_{2}$ IMes-containing analogue 3 , the $\mathrm{Ru}-\mathrm{C}_{\text {carbene }}$ distances are $\approx$ 0.04-0.05 $\AA$ shorter and the Ru-O distances are 0.04-0.09 $\AA$ longer than in complex 3 (see the Supporting Information).[6] These observations are consistent with the increased $\sigma$ donating properties of ligands $\mathbf{5}$ a,b over their NHC counterparts.

In all solid-state structures obtained, the CAAC exhibits the same orientation relative to the benzylidene group (Figure 4). The $\mathrm{N}$-aryl ring is located above the benzylidene moiety, while the quaternary carbon adjacent to the carbene center is positioned over an empty coordination site. In the case of pyridine complexes $\mathbf{7 a}, \mathbf{b}$, this observed preference may be due to $\pi-\pi$ stacking between the $\mathrm{N}$-aryl ring and the benzylidene ring. For chelating ether complexes 12a,b this structural preference may be a result of negative steric interactions between the Me groups on the quaternary carbon adjacent to the carbene carbon and the benzylidene proton (Figure 4). From this side view, it is apparent that the benzylidene proton would be in close contact with one Me group on the quaternary carbon center if the ligand were rotated $180^{\circ}$ relative to the remainder of the molecule.

${ }^{1} \mathrm{H}$ NMR spectroscopy data suggest that the solid-state conformation of $\mathbf{1 2 a}, \mathbf{b}$ is maintained in solution. 2D-ROESY experiments performed on complexes 12 a,b in $\mathrm{C}_{6} \mathrm{D}_{6}$ at $22{ }^{\circ} \mathrm{C}$ demonstrate Overhauser effects between the benzylidene resonance and the aryl protons on the $N$-DIPP moiety, the equivalent methine resonances of the aryl isopropyl groups, and the enantiotopic Me groups facing the benzylidene proton (Figure 4b). Overhauser effects are not observed between the benzylidene proton and the gem-dimethyl(ene) groups adjacent to the carbene center. This interaction might be expected if there is fast exchange between two orientations of the carbene ligand relative to the ruthenium benzylidene.

The efficiency of catalysts $\mathbf{1 2 a} \mathbf{a}, \mathbf{b}$ was examined in the ring-closing metathesis of $\mathbf{9}, \mathbf{1 3 a}$, and 13b [Eq. (4)]. At a catalyst<smiles>[R]C(=C)CC([R])([R])CC(=C)C</smiles>

13a: $R^{\prime}=H$

13b: $R^{\prime}=M e$

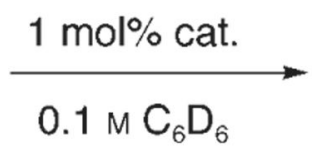

$\mathrm{R}=\mathrm{CO}_{2} \mathrm{Et}$<smiles>[R]C1=C(C)CC([R])([R])C1</smiles>

14a: $R^{\prime}=H$

14b: $R^{\prime}=M e$ 
loading of 1 mol\% catalyst loading, chelating ether catalysts 12a,b achieved $97 \%$ and $95 \%$ conversion of diethyl diallyl-malonate $(9)$ after heating at $60^{\circ} \mathrm{C}$ for $3.3 \mathrm{~h}$ and $10 \mathrm{~h}$, respectively. Uninitiated catalyst is observed for both catalysts even at high conversions, indicating that only a fraction of added catalyst is engaged in the reaction. Catalyst 12a converts 13a to $95 \%$ of trisubstituted olefin 14a in $20 \mathrm{~h}$ at $60^{\circ} \mathrm{C}$, whereas catalyst $\mathbf{1 2 b}$ achieves $96 \%$ conversion after $48 \mathrm{~h}$ at $60^{\circ} \mathrm{C}$. However, catalysts $\mathbf{1 2 a}, \mathbf{b}$ showed no reactivity in the conversion of $\mathbf{1 3 b}$ to tetrasubstituted olefin $\mathbf{1 4 b}$.

We hypothesized that sterics could be responsible for the lower activity of catalysts 12a,b relative to $\mathbf{2}$ and $\mathbf{3}$. CAACs without the quaternary carbon center adjacent to the carbene carbon are not synthetically accessible; thus, decreasing the steric bulk of the $\mathrm{N}$-aryl ring was targeted. Both the $N$-mesityl- and $N$-DEP (DEP=2,6-diethylphenyl)-substituted salts, 15 and 16, respectively, were synthesized; deprotonation of $\mathbf{1 5}$ and $\mathbf{1 6}$ under a variety of conditions did not afford the desired free carbenes [Eq. (5)]. In situ deprotonations of $\mathbf{1 5}$ and $\mathbf{1 6}$ with KHMDS at $-78^{\circ} \mathrm{C}$ in THF in the presence of ruthenium precursor $\mathbf{1 1}$ were also attempted. Although 17 was not observed by NMR spectroscopy, complex 18 could be

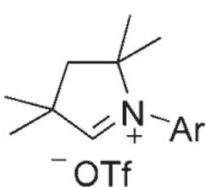

15: $\mathrm{Ar}=$ mesityl

16: $\mathrm{Ar}=2,6$ diethylphenyl

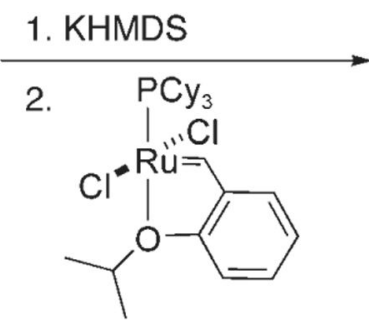

11<smiles>CC(C)Oc1ccccc1Cl</smiles>

17: $\mathrm{Ar}=$ mesityl $0 \%$

18: $\mathrm{Ar}=2,6-$ diethylphenyl $18 \%$

observed and isolated. Similar to 12a,b, complex $\mathbf{1 8}$ is an air-and moisture-stable solid. X-ray diffraction studies of catalyst $\mathbf{1 8}$ show similar bond lengths and angles to those in $12 \mathbf{1 2 a}, \mathbf{b}$ (Figure 5).

Catalyst 18, which differs from 12a only by replacement of $N$-DIPP with $N$-DEP, demonstrates significantly increased activity in the formation of di- and trisubstituted olefins. In the presence of $1 \mathrm{~mol} \% \mathbf{1 8}, 95 \%$ conversion of $\mathbf{9}$ to substituted cyclopentene $\mathbf{1 0}$ is observed in $15 \mathrm{~min}$ at 30 ${ }^{\circ} \mathrm{C}$, as compared to $3 \mathrm{~h}$ at $60^{\circ} \mathrm{C}$ required for catalyst 12a (Table 1). Catalyst 18 achieves $95 \%$ conversion of 13a to trisubstituted cyclopentene $14 \mathbf{a}$ at $30^{\circ} \mathrm{C}$ in $1 \mathrm{~h}$, which is comparable to the performance of catalysts $\mathbf{2}$ and $\mathbf{3}$. However, catalyst $\mathbf{1 8}$ showed no reactivity in the conversion of $\mathbf{1 3 b}$ to $\mathbf{1 4 b}$.

The dramatic increase in activity observed after slightly decreasing the steric bulk of the Naryl group is attributed to catalyst initiation. We postulate that catalyst initiation requires dissociation of the ether moiety and rotation of the benzylidene ring into a plane parallel to the $\mathrm{N}$-aryl group to open a coordination site for incoming olefin. [20] For complexes 12a,b this process may be sterically unfavorable, thus resulting in poor initiation (Figure 6). The steric bulk of the ortho-aryl substituents may have a significant effect on initiation for two reasons. First, the $\mathrm{Ru}-\mathrm{C}_{\text {carbene }}$ bond length is slightly shorter than in $\mathrm{NHC}$ analogues, thus bringing the aryl ring in closer proximity to the ruthenium center. Second, the quaternary carbon adjacent to the $\mathrm{N}$-aryl group restricts rotation around the $\mathrm{N}$-aryl bond and the $\mathrm{C}_{\text {aryl }}-\mathrm{C}_{i \mathrm{Pr}}$ bond, as indicated by NMR spectroscopy experiments discussed earlier. 
Interestingly, replacement of the $N$-mesityl groups in complex 3 with $N$-DIPP groups,[21] results in a catalyst with increased activity for the ring-closing metathesis of 9 (97\% conversion in 13 min vs. $20 \mathrm{~min}$ ).[20] However, this bulkier catalyst differs from the CAAC complexes owing to the absence of substitution at the carbon adjacent to the nitrogen atom.

Our investigation of the use of CAACs as ligands for olefin metathesis catalysts has shown promising results. By tuning the steric bulk of the $\mathrm{N}$-aryl group, the results of ring-closing metathesis for the formation of di- and trisubstituted olefins are comparable to those achieved with standard catalysts $\mathbf{2}$ and $\mathbf{3}$.

\section{References}

1. Grubbs, RH. Handbook of Metathesis. Weinheim: Wiley-VCH; 2003.

2. Ivin, KJ.; Mol, JC. Olefin Metathesis and Metathesis Polymerization. San Diego, CA: Academic Press; 1997.

3. Schwab P, Grubbs RH, Ziller JW. J. Am. Chem. Soc 1996;118:100-110.

4. Nguyen ST, Grubbs RH, Ziller JW. J. Am. Chem. Soc 1993;115:9858-9859.

5. Scholl M, Ding S, Lee CW, Grubbs RH. Org. Lett 1999;1:953-956. [PubMed: 10823227]

6. Garber SB, Kingsbury JS, Gray BL, Hoveyda AH. J. Am. Chem. Soc 2000;122:8168-8179.

7. Yun J, Marinez ER, Grubbs RH. Organometallics 2004;23:4172-4173.

8. Despagnet-Ayoub E, Grubbs RH. Organometallics 2005;24:338-340.

9. Berlin JM, Campbell K, Ritter T, Funk TW, Chlenov A, Grubbs RH. Org. Lett 2007;9:1339-1342. [PubMed: 17343392]

10. Stewart IC, Ung T, Pletnev AA, Berlin JM, Grubbs RH, Schrodi Y. Org. Lett 2007;9:1589-1592. [PubMed: 17378575]

11. Sanford MS, Love JA, Grubbs RH. J. Am. Chem. Soc 2001;123:6543-6554. [PubMed: 11439041]

12. Lavallo V, Canac Y, Prasang C, Donnadieu B, Bertrand G. Angew. Chem 2005;117:58515855.Angew. Chem. Int. Ed 2005;44:5705-5709.

13. Lavallo V, Canac Y, DeHope A, Donnadieu B, Bertrand G. Angew. Chem 2005;117:74027405.Angew. Chem. Int. Ed 2005;44:7236-7239.

14. Cavallo L. J. Am. Chem. Soc 2002;124:8965-8973. [PubMed: 12137552]

15. Romero PE, Piers WE. J. Am. Chem. Soc 2007;129:1698-1704. [PubMed: 17243686]

16. Jazzar R, Rian D, Bourg J-B, Donnadieu B, Canac Y, Bertrand G. Angew. Chem 2007;119:29572960.Angew. Chem. Int. Ed 2007;46:2899-2902.

17. Sanford MS, Love JA, Grubbs RH. Organometallics 2001;20:5314-5318.

18. Dias, EL. PhD Thesis. Pasadena CA (USA): California Institute of Technology; 1998.

19. Ritter T, Hejl A, Wenzel AG, Funk TW, Grubbs RH. Organometallics 2006;25:5740-5745.

20. Hejl, AH. PhD Thesis. Pasadena, CA (USA): California Institute of Technology; 2007.

21. Courchay FC, Sworen JC, Wagener KB. Macromolecules 2003;36:8231-8239. 


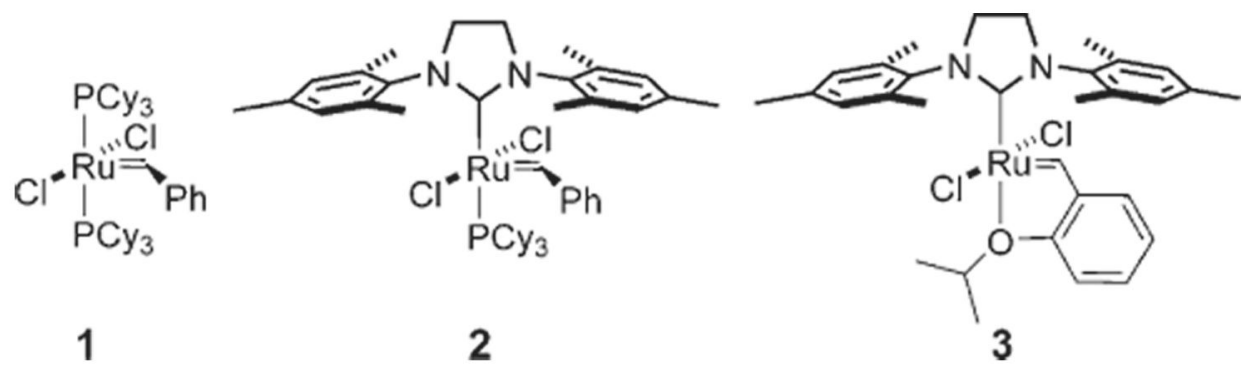

Figure 1.

Commonly utilized ruthenium olefin metathesis catalysts. $\mathrm{Cy}=$ cyclohexyl. 

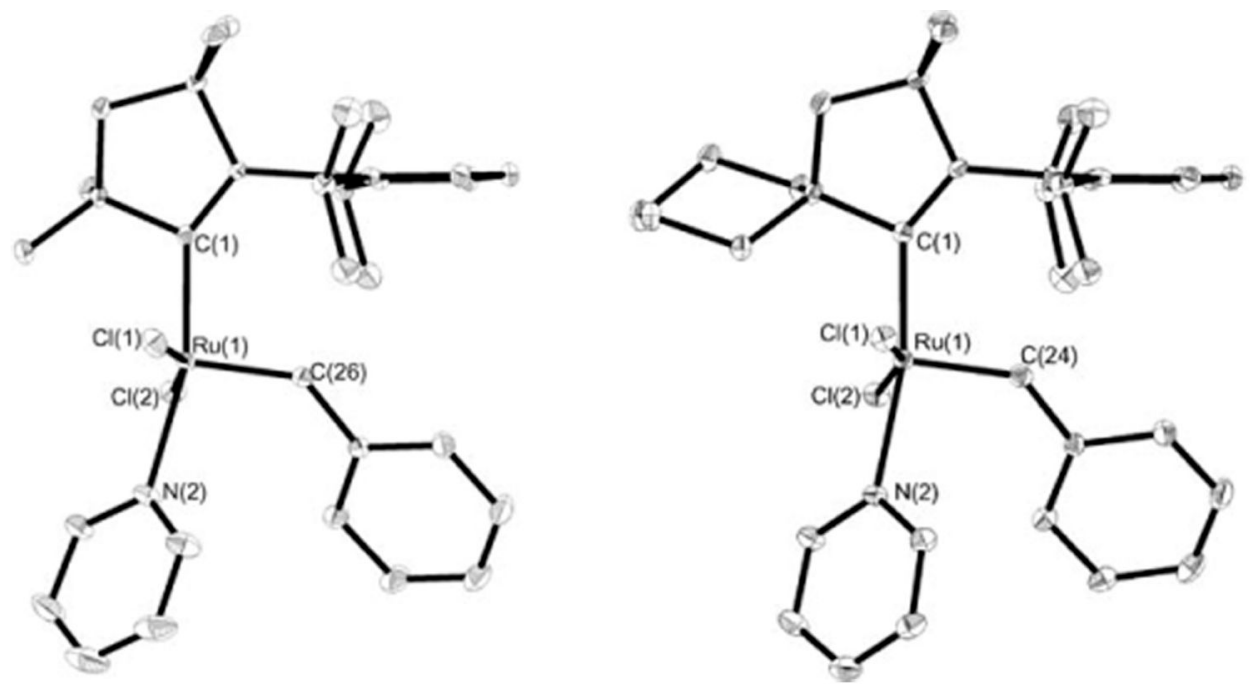

Figure 2.

X-ray crystal structures of $\mathbf{7 a}$ (left) and $\mathbf{7 b}$ (right). Thermal ellipsoids are drawn at 50\% probability and hydrogen atoms are omitted for clarity. 

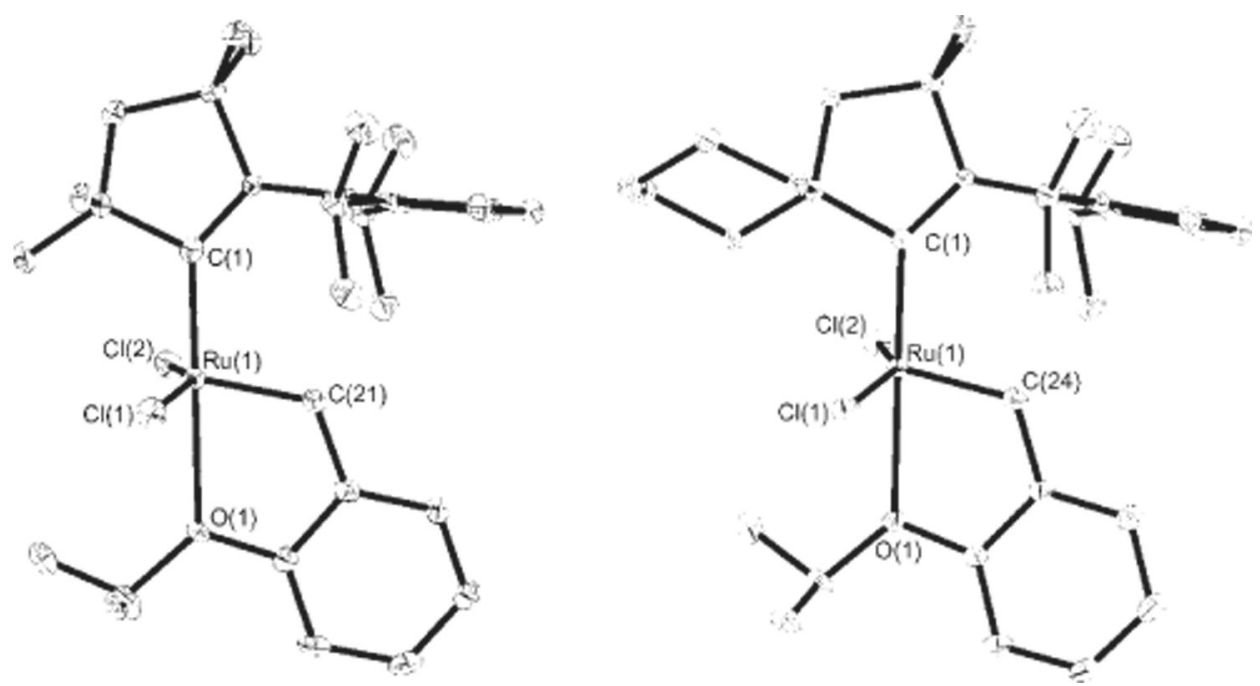

Figure 3.

X-ray crystal structures of 12a (left) and 12b (right). Thermal ellipsoids are drawn at 50\% probability and hydrogen atoms are omitted for clarity. 
a)

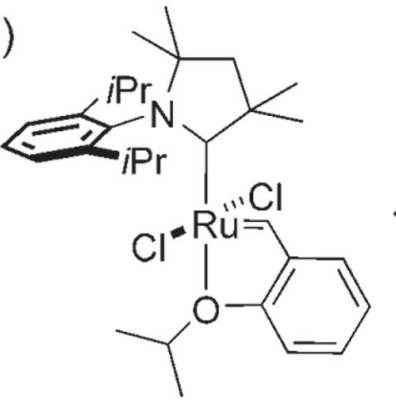

unobserved

conformation

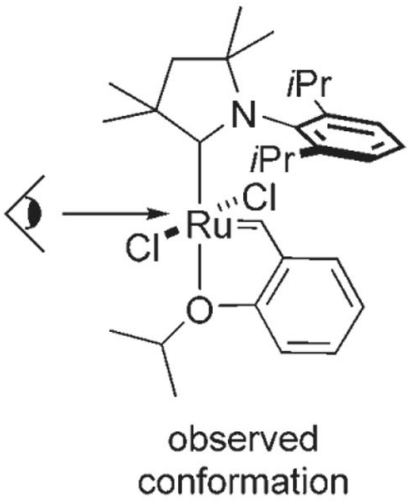

b)

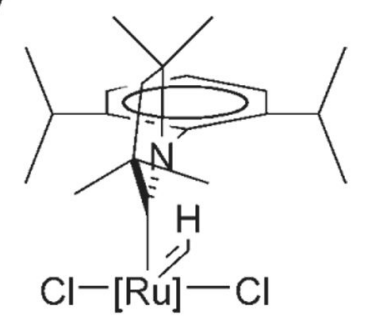

Figure 4.

View of complex 12a looking down the Ru=CHR bond. It can be observed that rotating the carbene $180^{\circ}$ would place the protons on the benzylidene and Me group on the quaternary carbon center in close proximity. 

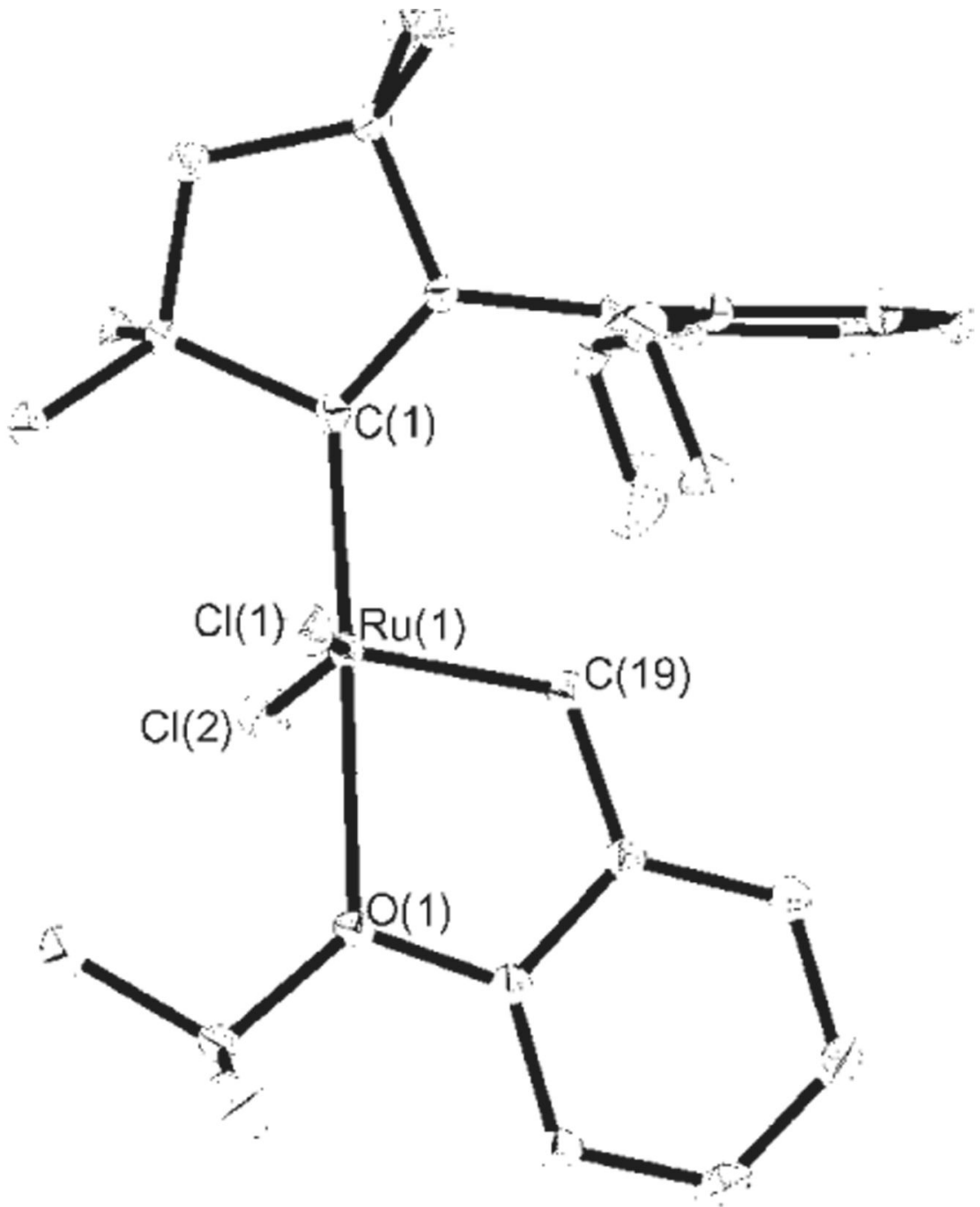

Figure 5.

$\mathrm{X}$-ray crystal structure of $\mathbf{1 8}$. Thermal ellipsoids are drawn at 50\% probability and hydrogen atoms are omitted for clarity. 

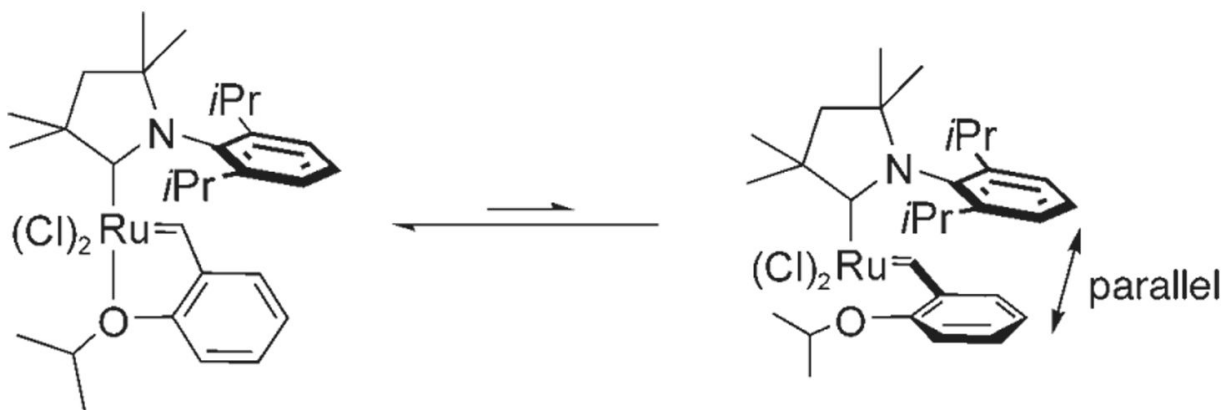

$12 a$

Figure 6.

Proposed rotation required for catalyst initiation. 


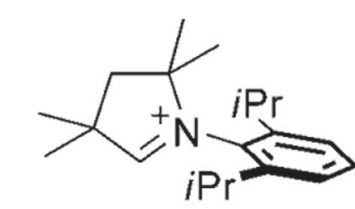

- OTf $4 a$

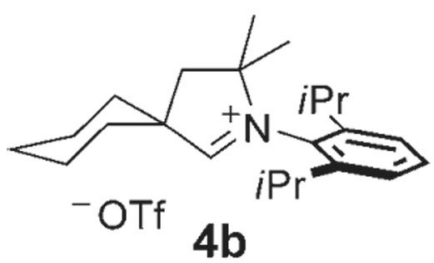

KHMDS $\overrightarrow{\mathrm{C}_{6} \mathrm{D}_{6}, 22^{\circ} \mathrm{C}}$

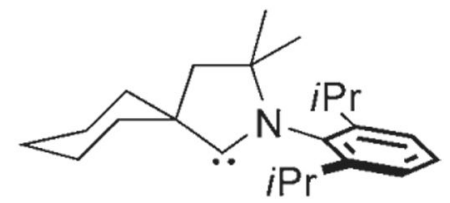

$5 b$

Scheme 1.

Synthesis of carbenes $\mathbf{5 a , b .}$ 
Table 1

Comparison of the activities of catalysts $12 \mathbf{a}, \mathbf{1 2 b}, \mathbf{1 8}, \mathbf{2}$, and 3 .

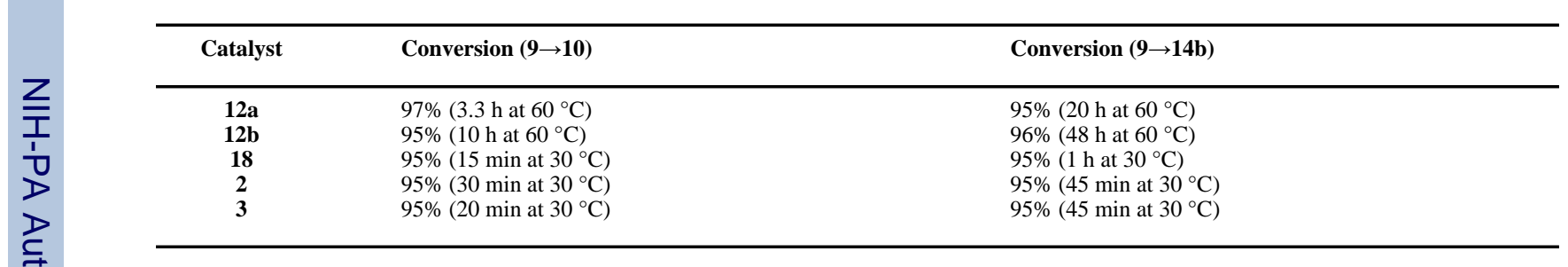

